\title{
ANÁLISE MICROSCÓPICA FOLIAR DE MUTAMBA (Guazuma ulmifolia LAM., MALVACEAE)
}

\section{MICROSCOPIC ANALYSIS OF THE LEAF OF WEST INDIAN ELM (Guazuma ulmifolia LAM., MALVACEAE)}

\author{
DUARTE, M. R. ${ }^{1 *}$; DRANKA, E. R. K. ${ }^{2}$; YANO, M. ${ }^{3}$
}

\author{
${ }^{1}$ Laboratório de Farmacognosia, Departamento de Farmácia, Universidade Federal do Paraná (UFPR), \\ Av. Pref. Lothário Meissner, 632, Jardim Botânico, 80210-170, Curitiba, PR, Brasil \\ ${ }^{2}$ Bolsista PIBIC/CNPq, Curso de Farmácia, UFPR \\ ${ }^{3}$ Universidade Católica Dom Bosco, Campo Grande, MS, Brasil \\ *Autor para correspondência: Márcia R. Duarte. E-mail: marciard@ufpr.br
}

\section{RESUMO}

Guazuma ulmifolia Lam. é uma planta arbórea, nativa das Américas e reposicionada atualmente na família Malvaceae. É conhecida comumente como mutamba ou chicomagro, e utilizada na medicinal popular como cicatrizante e no tratamento de distúrbios gastrointestinais e respiratórios. Estudos fitoquímicos indicaram a presença de taninos e flavonoides nos órgãos vegetativos aéreos. Ensaios farmacológicos comprovaram as atividades gastroprotetora e antibacteriana de extratos da planta. Ao analisar a anatomia foliar de G. ulmifolia, este trabalho buscou estabelecer os caracteres estruturais de fácil reconhecimento para a identificação microscópica dessa potencial droga vegetal. O material foi coletado de espécimes cultivados no Cerrado. Estudaramse o terço inferior do limbo e o pecíolo de folhas adultas, por meio de observações feitas em microscopia fotônica e eletrônica de varredura. Testes microquímicos foram também conduzidos com reativos usuais. Em ambas as faces epidérmicas, ocorrem tricomas estelares e glandulares. Os primeiros são formados por tricomas tectores unicelulares, reunidos pela base. Os glandulares são capitados, apresentando um pedicelo curto e glândula ovoide. A cutícula é nitidamente estriada e os estômatos são anomocíticos e restritos à superfície abaxial. O mesofilo é dorsiventral e a nervura central tem secção biconvexa e é percorrida por um único feixe vascular em arco aberto, envolto sucessivamente por bainhas esclerenquimática e parenquimática, esta contendo compostos fenólicos. O pecíolo tem contorno circular e um ou mais feixes vasculares colaterais. Ocorrem células com conteúdo mucilaginoso e fenólico na folha, bem como cristais prismáticos de oxalato de cálcio.

Palavras-chave: anatomia, chico-magro, mucilagem, planta medicinal, Sterculiaceae

\begin{abstract}
Guazuma ulmifolia Lam. is a woody plant indigenous to America and included currently in Malvaceae. It is commonly known as West Indian elm or bastard cedar, and used in folk medicine as wound healing and for treating gastrointestinal and respiratory problems. Phytochemical investigations identified tannins and flavonoids in the aerial vegetative parts. Pharmacological assays demonstrated gastroprotector and antibacterial effects. Studying the leaf anatomy of G. ulmifolia, this work aimed to establish structural characters, easily recognizable for the microscopic identification of this potential vegetal drug. The plant material was collected from grown specimens in the Brazilian savannah called Cerrado. It was studied the lower third of the blade and the
\end{abstract}


petiole from mature leaves, by means of light and scanning electron microscopy. Microchemical tests were also performed with standard reagents. In both surfaces, there are star-shaped and glandular trichomes. The former are unicellular non-glandular trichomes, assembled at the base. The glandular ones are capitate, presenting short stalk and ovoid head. The cuticle is striated and the stomata are anomocytic and restricted to the abaxial side. The mesophyll is dorsiventral and the midrib has biconvex contour. It is traversed by one single collateral vascular bundle, in open arc and encircled successively by sclerenchymatic and parenchymatic bundle sheaths, the latter containing phenolic compounds. The petiole has circular shape and one or more collateral vascular bundles. It is found cells bearing mucilage and phenolic compounds in the leaf, as well as prismatic crystals of calcium oxalate.

Keywords: anatomy, bastard cedar, medicinal plant, mucilage, Sterculiaceae

\section{INTRODUÇÃO}

A espécie Guazuma ulmifolia Lam., anteriormente enquadrada na família Sterculiaceae, encontra-se reposicionada em Malvaceae, em razão de estudos filogenéticos (SOUZA, LORENZI, 2008). É encontrada desde o México até o Sul do Brasil (CARVALHO, 2007), sendo comum no Cerrado, no Pantanal e em orlas de rios, onde é popularmente conhecida como mutamba, araticum-bravo ou chico-magro, entre outros nomes. Apresenta-se como uma arvoreta a árvore perenifólia, com copa arredondada e densa, galhos horizontais, folhas alternas, simples, pilosas e ovaladas a lanceoladas, inflorescências amarelas e frutos globosos, secos e verrucosos (LORENZI, MATOS, 2002; CARVALHO, 2007).

Possui importância econômica, uma vez que os frutos e as sementes são comestíveis, as flores são melíferas, do caule obtém-se pasta celulósica, enquanto que os órgãos vegetativos são utilizados na medicina popular. Às folhas e raízes são atribuídas ações antidiarreica e cicatrizante, e por sua vez caules e cascas costumam ser indicados para o tratamento de distúrbios respiratórios e gastrointestinais (HEINRICH et al., 1998; LORENZI, MATOS, 2002; FENNER et al., 2006; AGRA, FREITAS, BARBOSA-FILHO, 2007; CARVALHO, 2007; VERA-KU et al., 2010).

Estudos fitoquímicos revelaram a presença de alcaloides e taninos na infusão da casca caulinar (ANDRADE-CETTO, HEINRICH, 2005), bem como a presença de saponinas triterpenoides (CARVALHO, 2007). A investigação de Galina et al. (2005) corroborou parcialmente esses dados, ao detectar taninos, saponinas, flavonoides e mucilagem nas cascas. No entanto, Ortega et al. (1998) obtiveram resultados diversos. Para esses autores, embora taninos estejam presentes em folhas e caules de $G$. ulmifolia, alcaloides, saponinas ou cianoglicosídeos não foram detectados.

A atividade antibacteriana de extratos obtidos da casca caulinar foi comprovada em diferentes ensaios (FERNANDES, SANTOS, PIMENTA, 2005; 
LIMA et al., 2006) e evidenciou-se efeito gastroprotetor (BERENGUER et al., 2007) e anti-hiperglicêmico (ALARCON-AGUILARA et al., 1998; ALONSO-CASTRO, SALAZAR-OLIVO, 2008) das partes aéreas de G. ulmifolia. Felipe et al. (2006) comprovaram a inibição viral, enquanto que a pesquisa de Magos et al. (2008) evidenciou ação hipotensora de extratos da espécie.

Diante do crescente interesse que essa espécie tem despertado como medicinal e as insuficientes informações que possibilitem a sua utilização na prática terapêutica, o presente trabalho objetivou investigar os caracteres anatômicos foliares de G. ulmifolia de fácil reconhecimento, para subsidiar a identificação microscópica dessa potencial droga vegetal.

\section{MATERIALE MÉTODOS}

\subsection{MATERIALBOTÂNICO}

Amostras de folhas adultas de Guazuma ulmifolia Lam. (Malvaceae), obtidas a partir do quarto nó foliar, foram coletadas de exemplares cultivados a pleno sol no Cerrado, nos arredores de Campo Grande, Mato Grosso do Sul (aproximadamente nas coordenadas $20^{\circ} 26^{\prime} \mathrm{S}$ e $54^{\circ} 29^{\prime} \mathrm{O}$ e na altitude de $517 \mathrm{~m}$ ), em março de 2008 . A exsicata foi registrada no Herbário da Universidade Federal de Mato Grosso do Sul como CGMS 25727. O material foliar foi dessecado à temperatura ambiente e transportado ao Laboratório de Farmacognosia, Departamento de Farmácia, Universidade Federal do Paraná para ser processado, de acordo com técnicas usuais de microscopia fotônica (MF) e eletrônica de varredura (MEV).

\subsection{METODOLOGIA}

Para a análise microscópica, as folhas dessecadas foram reidratadas e fixadas em FAA70 (JOHANSEN, 1940), sendo então preservadas em etanol a $70 \%(\mathrm{v} / \mathrm{v})$ (BERLYN, MIKSCHE, 1976). O terço inferior da lâmina foliar e o pecíolo foram seccionados à mão livre, nos sentidos transversal e longitudinal, incluindo paradérmico, e corados com azul de astra e fucsina básica (ROESER, 1972). Adicionalmente, fragmentos foliares foram desidratados em série etanólica crescente, infiltrados e emblocados em glicol-metacrilato, seccionados em micrótomo de rotação e corados com azul de toluidina(O'BRIEN, FEDER, McCULLY, 1964).

Testes microquímicos foram realizados para elucidar o conteúdo das células e a impregnação das paredes celulares, a saber: evidenciação de lignina com floroglucina clorídrica (FOSTER, 1949), amido com lugol (BERLYN, MIKSCHE, 1976), substâncias lipofílicas com Sudan III (SASS, 1951), mucilagem com azul de metileno (OLIVEIRA, AKISUE, 1997), cristais de cálcio com ácido sulfúrico diluído (OLIVEIRA, AKISUE, 1997) e compostos fenólicos com cloreto férrico(JOHANSEN, 1940). 
Para a microscopia eletrônica de varredura(SOUZA, 1998), fragmentos foliares foram desidratados sequencialmente em série etanólica e pelo ponto crítico de $\mathrm{CO}_{2}$, montados em suporte, metalizados com ouro e examinados em alto vácuo.

\section{RESULTADOS}

Em vista frontal de ambas as faces da lâmina foliar, observam-se tricomas estelares (Figuras 1, 2, 5), que consistem de quatro a nove tricomas tectores unicelulares, reunidos pela base, de paredes espessadas e ponta aguda. Ocorrem também tricomas glandulares (Figuras 3,4 ), capitados, de pedicelo relativamente curto e glândula ovoide, inseridos no mesmo nível das demais células epidérmicas. A cutícula é nitidamente estriada (Figura 6) e reveste a epiderme formada de células com paredes anticlinais praticamente retas (Figuras 7, 8). Encontram-se estômatos anomocíticos exclusivamente na face epidérmica abaxial (Figura 8), tipicamente de folha hipoestomática.

Em secção transversal, as células-guarda localizam-se no mesmo plano das células adjacentes, a cutícula mostra-se moderadamente espessada e a epiderme é unisseriada (Figura 11). As células da face adaxial são maiores que às da abaxial (Figura 10) e, de um modo geral, se distinguem pelo maior contéudo mucilaginoso e fenólico.

O mesofilo é dorsiventral (Figura 10), constituído de cerca de quatro estratos de parênquima paliçádico e cinco de parênquima esponjoso pouco diferenciado. Feixes vasculares colaterais, de pequeno porte, distribuem-se no mesofilo (Figura 10). Possuem calotas esclerenquimáticas apostas ao xilema e ao floema, e são circundados por uma bainha parenquimática rica em compostos fenólicos, assumindo uma posição transcurrente.

A nervura central apresenta secção transversal biconvexa (Figura 9). Junto a ambas as superfícies, ocorrem algumas camadas de colênquima do tipo angularanelar (Figuras 12, 14). Há um único feixe vascular colateral (Figuras 9, 13), em arco aberto e envolto por uma bainha esclerenquimática completa e externamente por uma bainha parenquimática conspícua, constituída de células contendo compostos fenólicos (Figuras 9, 12).

O pecíolo possui secção aproximadamente circular (Figura 15). Na região distal (Figuras 15, 16), podem ser encontrados um ou mais feixes vasculares colaterais dispostos em arco fechado, envoltos por uma bainha esclerenquimática completa, enquanto que na proximal, o sistema vascular assume arranjo cêntrico, em que o cilindro floemático é externo ao xilema (Figura 17).

Células com conteúdo fenólico e mucilaginoso (Figuras 9-12, 14, 16), bem como 
com cristais prismáticos de oxalato de cálcio (Figuras 12-14, 16, 17) ocorrem em toda a folha, sendo que há maior concentração de compostos fenólicos nas proximidades do sistema vascular.

\section{DISCUSSÃO}

Com base nas informações de filogenia, atualmente complementadas pelas técnicas de biologia molecular que aprofundam o conhecimento sobre as relações evolutivas entre as espécies vegetais, a família Sterculiaceae foi incluída em Malvaceae (SOUZA, LORENZI, 2008). Considerando esse reposicionamento taxonômico, os caracteres anatômicos observados em Guazuma ulmifolia Lam. revelam-se concordantes com os aspectos marcantes do grupo, tais como: presença de tricomas estelares e glandulares, cristais prismáticos de oxalato de cálcio, células contendo compostos fenólicos e células mucilaginosas localizadas na epiderme, principalmente nas da face adaxial, e nos parênquimas. Somam-se a essas características, outras menos notáveis, como mesofilo dorsiventral, células epidérmicas com paredes anticlinais retas e feixes vasculares de pequeno porte acompanhados de esclerênquima(METCALFE, CHALK, 1950; 1988).

Os aspectos verificados nesta investigação referentes a folha hipoestomática, com a ocorrência de estômatos anomocíticos (ranunculáceos) e feixes vasculares colaterais circundados por esclerênquima são mencionados para o gênero Guazuma por Metcalfe e Chalk(1950).

Resultados parcialmente semelhantes foram descritos por Galina et al. (2005) para a folha de G. ulmifolia. Informações discordantes às deste trabalho referem-se ao fato desses pesquisadores mencionarem a ocorrência de canais secretores na face adaxial da epiderme foliar e no parênquima do pecíolo. Analisando-se as figuras ilustrativas publicadas por Galina et al. (2005), os referidos canais secretores têm correspondência com as células mucilaginosas verificadas nesta investigação. Adicionalmente, esses autores não constataram a presença de tricomas glandulares.

Ainda, com relação às estruturas secretoras do gênero, Metcalfe e Chalk(1950) apresentam um diagrama do pecíolo de G. tomentosa Kunth, indicando a ocorrência de cavidades mucilaginosas em meio ao parênquima. Essas estruturas internas não foram confirmadas nesta análise.

Os dados obtidos no presente trabalho indicam que os caracteres que se destacam, pelo fato de serem úteis na identificação do material foliar de G. ulmifolia, consistem de cutícula estriada, tricomas estelares e glandulares capitados, cristais prismáticos de oxalato de cálcio e células contendo mucilagem e compostos fenólicos. 


\section{AGRADECIMENTOS}

Os autores são gratos ao Centro de Microscopia Eletrônica da UFPR pelas micrografias de varredura e ao PIBIC/CNPq pela bolsa concedida à E.R.K. Dranka.

\section{REFERÊNCIAS}

AGRA, M. F.; FREITAS, P. F.; BARBOSA-FILHO, J. M. Synopsis of the plants known as medicinal and poisonous in Northeast of Brazil. Rev. Bras. Farmacogn., João Pessoa, v. 17, n. 1, p. 114-140, 2007.

ALARCON-AGUILARA, F. J.; ROMAN-RAMOS, R.; PEREZ-GUTIERREZ, S.; AGUILAR-CONTRERAS, A.; CONTRERAS-WEBER, C. C.; FLORES-SAENZ, J. L. Study of the anti-hyperglycemic effect of plants used as antidiabetics. $\mathbf{J}$. Ethnopharmacol., Limerick, v. 61, p. 101-110, 1998.

ALONSO-CASTRO, A. J.; SALAZAR-OLIVO, L. A. The anti-diabetic properties of Guazuma ulmifolia Lam. are mediated by the stimulation of glucose uptake in normal and diabetic adipocytes without inducing adipogenesis. J. Ethnopharmacol., Limerick, v. 118, p. 252-256, 2008.

ANDRADE-CETTO, A.; HEINRICH, M. Mexican plants with hypoglycaemic effect used in the treatment of diabetes. J. Ethnopharmacol., Limerick, v. 99, p. 325-348, 2005.

BERENGUER, B.; TRABADELA, C.; SÁNCHEZ-FIDALGO, S.; QUÍlEZ, A.; MIÑO, P.; PUERTA, R.; MARTÍN-CALERO, M. J. The aerial parts of Guazuma ulmifolia Lam. protect against NSAID-induced gastric lesions. J. Ethnopharmacol., Limerick, v. 114, p. 153-160, 2007.

BERLYN, G. P.; MIKSCHE, J. P. Botanical microtechnique and cytochemistry. Ames: Iowa State University Press, 1976. 326 p.

CARVAlHO, P. E. R. Mutamba - Guazuma ulmifolia. Circular Téc. - Embrapa Flor., Colombo, v. 141, p. 1-13, 2007.

FELIPE, A. M. M.; RINCÃO, V. P.; BENATI, F. J.; LINHARES, R. E. C.; GALINA, K. J.; TOLEDO, C. E. M.; LOPES, G. C.; PALAZZO-DE-MELLO, J. C.; NOZAWA, C. Antiviral effect of Guazuma ulmifolia and Stryphnodendron adstringens on poliovirus and bovine herpesvirus. Biol. Pharm. Bull., Tokyo, v. 29, n. 6, p. 1092-1095, 2006.

FENNER, R.; BETTI, A. H.; MENTZ, L. A.; RATES, S. M. K. Plantas utilizadas na medicina popular brasileira com potencial atividade antifúngica. Rev. Bras. Ciên. Farm., São Paulo, v. 42, n. 3, p. 369-394, 2006.

FERNANDES, T. T.; SANTOS, A. T. F.; PIMENTA, F. C. Atividade antimicrobiana das plantas Plathymenia reticulata, Hymenaea courbaril e Guazuma ulmifolia. Rev. Patol. Trop., Goiânia, v. 34, n. 2, p. 113-122, 2005.

FOSTER, A. S. Practical plant anatomy. $2^{\text {nd }}$ ed. New York: D. Van Nostrand, 1949. 228 p. 
GALINA, K. J.; SAKURAGUI, C. M.; BORGUEZAM-ROCHA, J. C.; LORENZETTI, E. R.; PALAZZO-DE-MELLO, J. C. Contribuição ao estudo farmacognóstico de mutamba (Guazuma ulmifolia - Sterculiaceae). Acta Farm. Bonaerense, La Plata, v. 24, n. 2, p. 225-233, 2005.

HEINRICH, M.; ANKLI, A.; FREI, B.; WEIMANN, C.; STICHER, O. Medicinal plants in Mexico: healers' consensus and cultural importance. Soc. Sci. Med., Oxford, v. 47, n. 11 , p. 1859-1871, 1998.

JOHANSEN, D. A. Plant microtechnique. New York: McGraw-Hill Book, 1940. 523 p.

LIMA, M. R. F.; LUNA, J. S.; SANTOS, A. F.; ANDRADE, M. C. C.; SANT'ANA, A. E. G.; GENET, J. P.; MARQUES, B.; NEUVILLE, L.; MOREAU, N. Anti-bacterial activity of some Brazilian medicinal plants. J. Ethnopharmacol., Limerick, v. 105, p. 137-147, 2006.

LORENZI, H.; MATOS, F. J. A. Plantas medicinais do Brasil: nativas e exóticas. Nova Odessa: Plantarum, 2002.

MAGOS, G. A.; MATEOS, J. C.; PÁEZ, E.; FERNÁNDEZ, G.; LOBATO, C.; MÁRQUEZ, C.; ENRÍQUEZ, R. G. Hypotensive and vasorelaxant effects of the procyanidin fraction from Guazuma ulmifolia bark in normotensive and hypertensive rats. J. Ethnopharmacol., Limerick, v. 117, p. 58-68, 2008.

METCALFE, C. R.; CHALK, L. Anatomy of the dicotyledons: leaves, stem, and wood in relation to taxonomy, with notes on economic uses. Oxford: Clarendon, 1950.

METCALFE, C. R.; CHALK, L. Anatomy of the dicotyledons: systematic anatomy of the leaf and stem. $2^{\text {nd }}$ ed. Oxford: Clarendon, 1988. v. 1, 276 p.

O'BRIEN, T. P.; FEDER, N.; McCULLY, M. E. Polychromatic staining of plant cell walls by toluidine blue O. Protoplasma, Vienna, v. 59, n. 2, p. 368-373, 1964.

OLIVEIRA, F.; AKISUE, G. Fundamentos de farmacobotânica. 2.ed. São Paulo: Atheneu, 1997.178 p.

ORTEGA, M. E.; CARRANCO, M. E.; MENDOZA, G.; CASTRO, G. Chemical composition of Guazuma ulmifolia Lam. and its potential for ruminant feeding. Cuban J. Agric. Sci., La Habana, v. 32, n. 4, p. 383-386, 1998.

ROESER, K. R. Die Nadel der Schwarzkiefer-Massenprodukt und Kunstwerk der Natur. Mikrokosmos, Stuttgart, v. 61, n. 2, p. 33-36, 1972.

SASS, J. E. Botanical microtechnique. $2^{\text {nd }}$ ed. Ames: lowa State College Press, 1951. $228 \mathrm{p}$.

SOUZA, V. C.; LORENZI, H. Botânica sistemática. Nova Odessa: Instituto Plantarum, 2008. 704 p.

SOUZA, W. Técnicas básicas de microscopia eletrônica aplicadas às Ciências Biológicas. Rio de Janeiro: Sociedade Brasileira de Microscopia Eletrônica, 
1998. p. 1-44.

VERA-KU, M.; MÉNDEZ-GONZÁLEZ, M.; MOO-PUC, R.; ROSADO-VALLADO, M.; SIMÁ-POLANCO, P.; CEDILLO-RIVERA, R.; PERAZA-SÁNCHEZ, S. R. Medicinal potions used against infectious bowel diseases in Mayan traditional medicine. $\mathbf{J}$. Ethnopharmacol., Limerick, v. 132, p. 303-308, 2010.

\section{LEGENDAS}
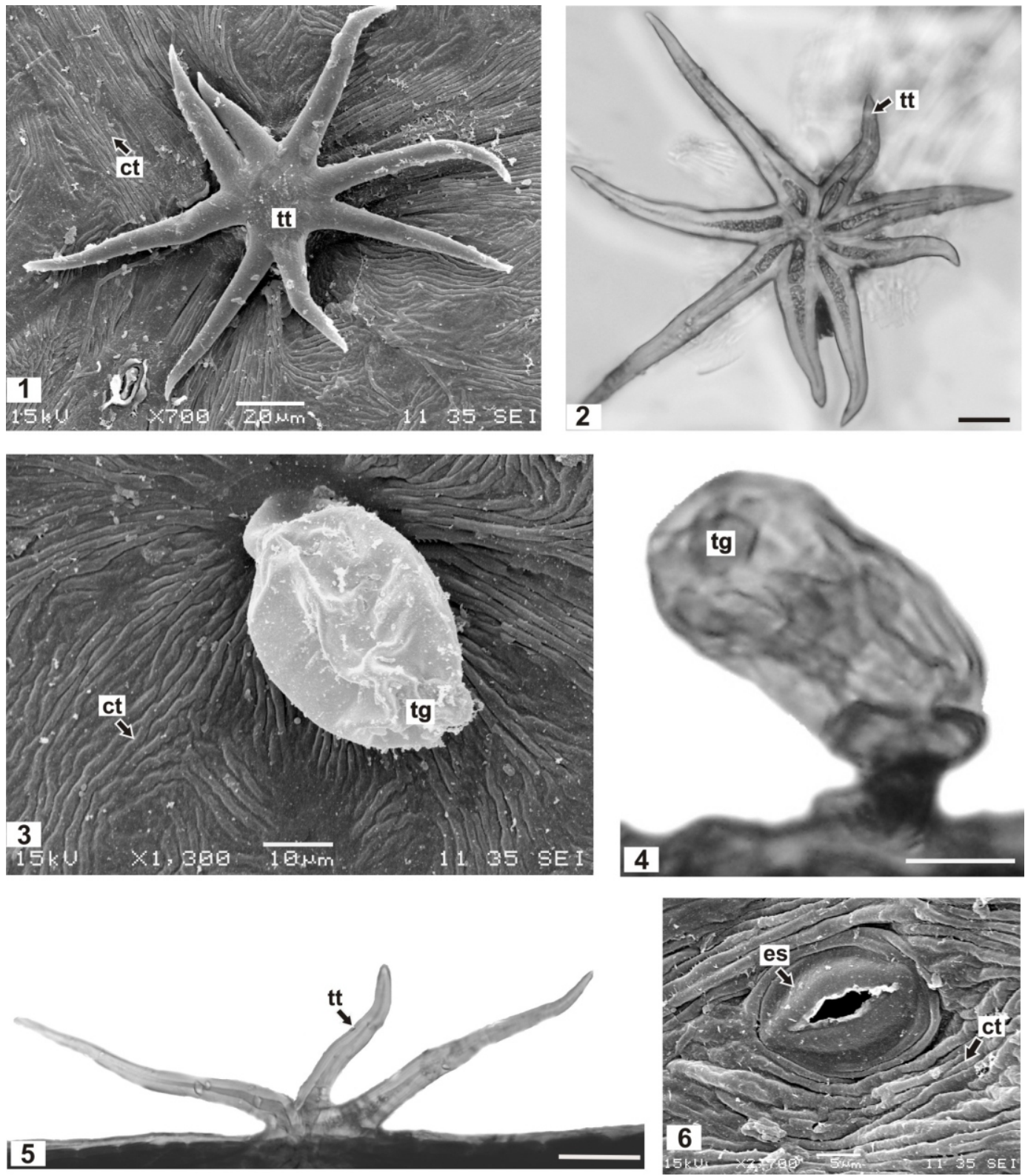

FIGURAS 1-6. Guazuma ulmifolia LAM., MALVACEAE - EPIDERME FOLIAR: 1, 2. TRICOMAS TECTORES DO TIPO ESTELAR, RESPECTIVAMENTE EM MEV E MF; 3, 4. TRICOMA GLANDULAR CAPITADO, EM MEV E MF; 5. DETALHE DA BASE DE UM TRICOMA ESTELAR; 6. PORMENOR DA CUTÍCULAESTRIADAE DE UM ESTÔMATO NAFACEABAXIAL. ABREVIATURAS: ct - CUTÍCULA, es - ESTÔMATO, MEV - MICROSCOPIA ELETRÔNICA DE VARREDURA, MF - MICROSCOPIA FOTÔNICA, $\mathbf{t g}-$ TRICOMA GLANDULAR CAPITADO, $\mathbf{t t}-$ TRICOMA ESTELAR. BARRA $=20 \mu \mathrm{m}(2,4-$ 6) 

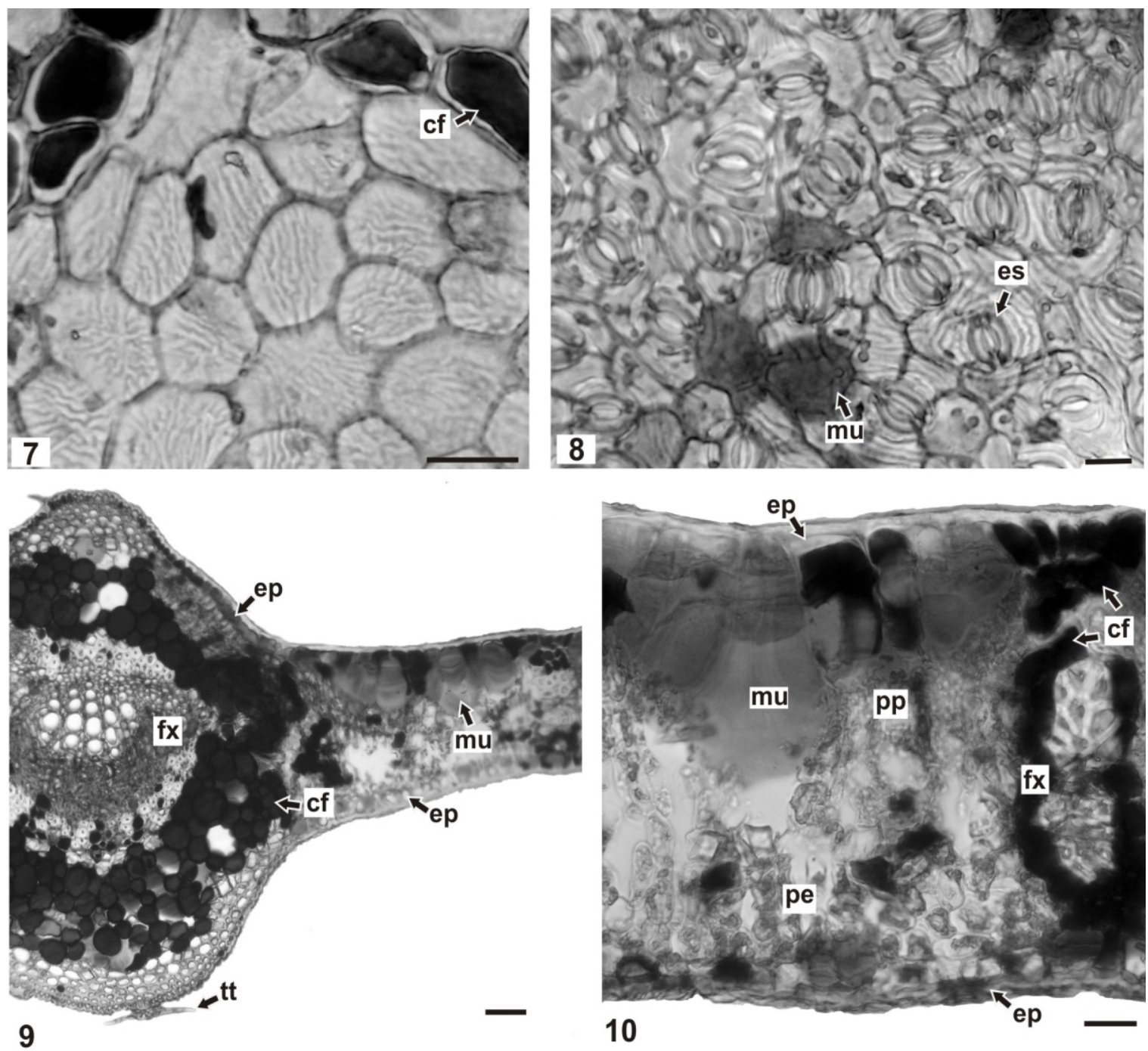

FIGURAS 7-10. Guazuma ulmifolia LAM., MALVACEAE - FOLHA: 7, 8. VISTA FRONTAL DA EPIDERME, FACES ADAXIAL E ABAXIAL, RESPECTIVAMENTE; 9. SECÇÃO TRANSVERSAL DA NERVURA CENTRAL E DE PARTE DA REGIÃO INTERNERVURAL; 10. REGIÃO INTERNERVURAL, MOSTRANDO MESOFILO DORSIVENTRAL E CÉLULAS COM CONTEÚDO MUCILAGINOSO E FENÓLICO. ABREVIATURAS: cf - CÉLULA COM COMPOSTOS FENÓLICOS, ep - EPIDERME, es ESTÔMATO, fx - FEIXE VASCULAR, mu - CÉLULA COM MUCILAGEM, pe - PARÊNQUIMA ESPONJOSO, pp - PARÊNQUIMA PALIÇÁDICO, tt - TRICOMA ESTELAR. BARRA = $20 \mu \mathrm{m}(7,8,10)$, $50 \mu \mathrm{m}(9)$ 

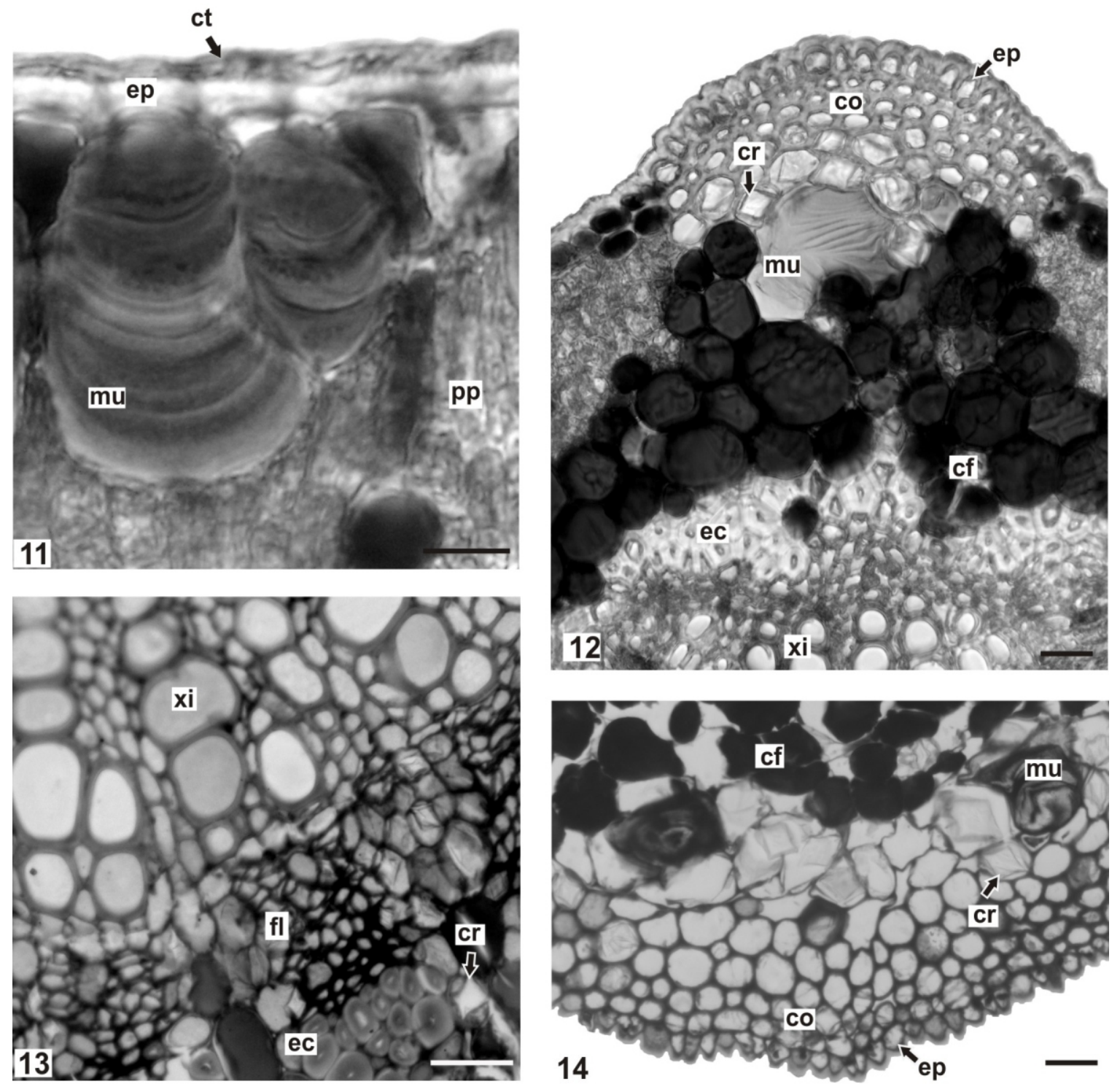

FIGURAS 11-14. Guazuma ulmifolia LAM., MALVACEAE - FOLHA, EM SECÇÃO TRANSVERSAL: 11. PORMENOR DE CÉLULAS CONTENDO MUCILAGEM; 12. PARTE DA NERVURA CENTRAL, MOSTRANDO CONTEÚDO FENÓLICO E MUCILAGINOSO DE CÉLULAS JUNTO À SUPERFÍCIE ADAXIAL; 13. FEIXE VASCULAR COLATERAL NA NERVURA CENTRAL; 14. DETALHE DA FACE ABAXIAL DA NERVURA CENTRAL. ABREVIATURAS: cf - CÉLULA COM COMPOSTOS FENÓLICOS, co - COLÊNQUIMA, cr - CRISTAL DE OXALATO DE CÁLCIO, ct - CUTÍCULA, ec ESCLERENNQUIMA, ep - EPIDERME, fl - FLOEMA, mu - CÉLULA COM MUCILAGEM, pp PARÊNQUIMAPALIÇÁDICO, xi - XILEMA. BARRA $=20 \mu \mathrm{m}$ 

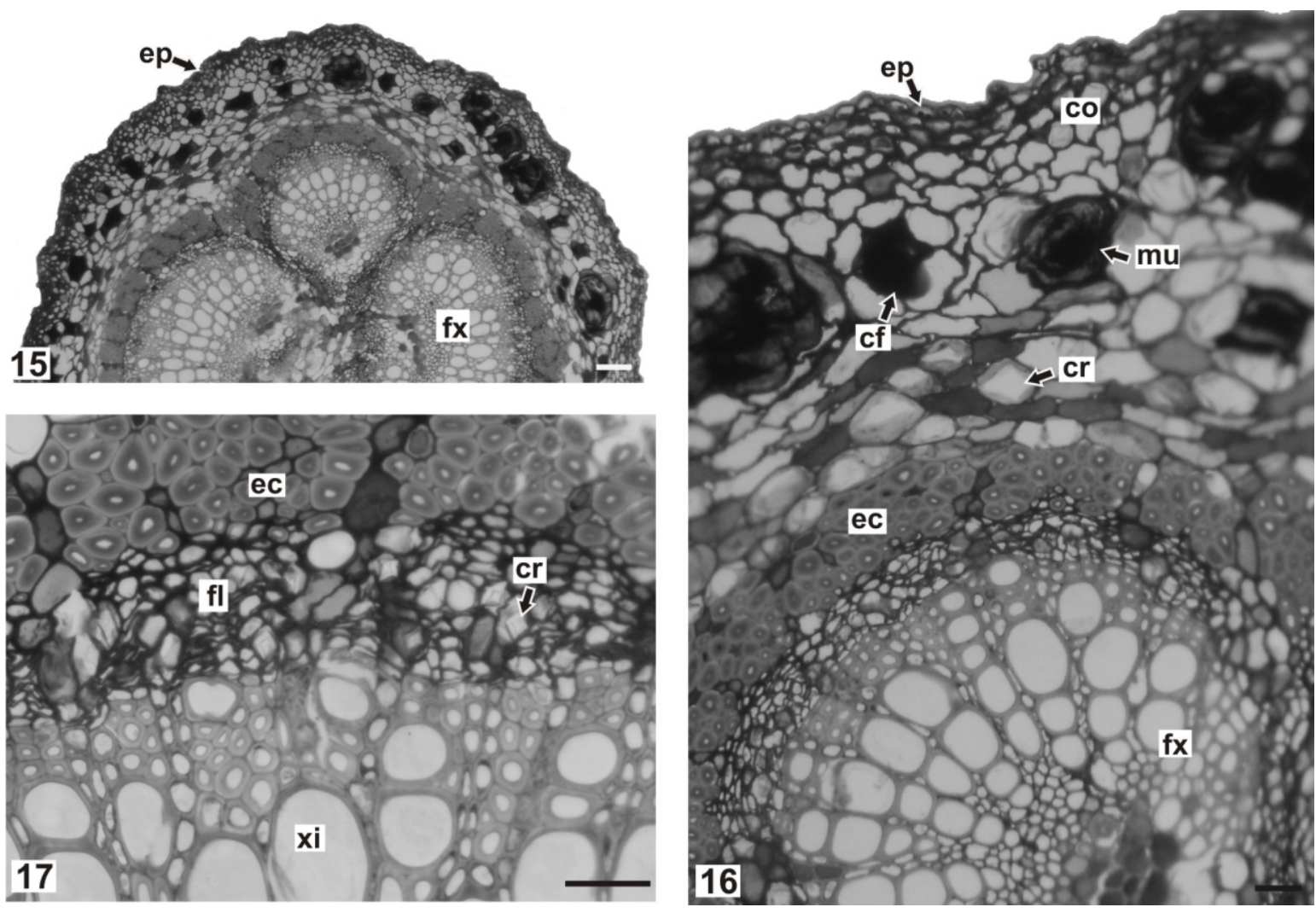

FIGURAS 15-17. Guazuma ulmifolia LAM., MALVACEAE - PECÍOLO, EM SECÇÃO TRANSVERSAL: 15. ASPECTO GERAL; 16. DETALHE DE EPIDERME, CÉLULAS COM MUCILAGEM E COMPOSTOS FENÓLICOS E ESCLERÊNQUIMAENVOLVENDO FEIXE VASCULAR; 17. PORMENOR DE UM FEIXE VASCULAR COLATERAL. ABREVIATURAS: cf - CÉLULA COM COMPOSTOS FENÓLICOS, co COLÊNQUIMA, cr - CRISTAL DE OXALATO DE CÁLCIO, ec - ESCLERÊNQUIMA, ep - EPIDERME, fI - FLOEMA, fx - FEIXE VASCULAR, mu - CÉLULA COM MUCILAGEM, xi - XILEMA. BARRA = $20 \mu \mathrm{m}$ $(16,17), 50 \mu \mathrm{m}(15)$ 